\title{
Physical, Psychological, Social, and Existential Symptoms in Older Homeless-Experienced Adults: An Observational Study of the Hope Home Cohort
}

\author{
M. Patanwala, $B A^{7}$, L. Tieu, $\mathrm{MPH}^{2,3}$, C. Ponath, $\mathrm{MA}^{2}$, D. Guzman, MSPH ${ }^{2,3}$, C. S. Ritchie, MD, MSPH ${ }^{4,4}$, \\ and Margot Kushel, $M D^{2,3}$
}

'UCSF School of Medicine, San Francisco, CA, USA; ${ }^{2}$ UCSF Division of General Internal Medicine at Zuckerberg San Francisco General Hospital, San Francisco, CA, USA; ${ }^{3}$ UCSF Center for Vulnerable Populations, San Francisco, CA, USA; ${ }^{4}$ UCSF Division of Geriatrics, Department of Medicine, San Francisco, CA, USA.

BACKGROUND: The homeless population in the United States is aging. Aging-associated comorbidities are associated with increased symptoms.

OBJECTIVE: To describe the prevalence of symptoms among older homeless-experienced adults, analyze factors associated with moderate-high physical symptom burden, and identify symptom clusters.

DESIGN: Cross-sectional analysis within longitudinal cohort study.

PARTICIPANTS: Using population-based sampling from shelters, meal programs, encampments, and a recycling center in Oakland, CA, we recruited homeless adults aged $\geq 50$ for a longitudinal cohort. This study includes participants who participated in the 18-month follow-up visit.

MAIN MEASURES: We assessed physical symptoms using the Patient Health Questionnaire-15 (PHQ-15); psychological symptoms using the Center for Epidemiologic Studies Depression Scale (CES-D), Primary Care PTSD Screen (PC-PTSD), and psychiatric section of the Addiction Severity Index (ASI); loneliness using the Three-Item Loneliness Scale; and regret using a six-item regret scale. KEY RESULTS: Two hundred eighty-three participants (75.6\% men and 82.3\% African-Americans) completed symptoms interviews. Over a third (34.0\%) had moderate-high physical symptom burden. The most prevalent physical symptoms were joint pain, fatigue, back pain, and sleep trouble. Over half (57.6\%) had psychological symptoms; $39.6 \%$ exhibited loneliness and $26.5 \%$ had high regret. In a multivariate model, being a woman (AOR 2.54, 95\% CI 1.28-5.03), childhood abuse (AOR $1.88,95 \%$ CI 1.00-3.50), cannabis use (AOR 2.59, 95\% CI 1.38-4.89), multimorbidity (AOR 2.50, 95\% CI $1.36-$ 4.58), anxiety (AOR 4.30, 95\% CI 2.24-8.26), hallucinations (AOR 3.77, 95\% CI 1.36-10.43), and loneliness (AOR $2.32,95 \%$ CI 1.26-4.28) were associated with moderatehigh physical symptom burden. We identified four symptom clusters: minimal overall $(n=129)$, moderate overall ( $n=68)$, high physical and high psychological ( $n=67)$, and high physical and low psychological $(n=17)$.

Received April 17, 2017

Revised September 14, 2017

Accepted November 3, 2017

Published online November 28, 2017
CONCLUSIONS: Older homeless-experienced adults exhibit a high prevalence of symptoms across multiple dimensions. To reduce suffering, clinicians should recognize the interaction between symptoms and address multiple symptom dimensions.

KEY WORDS: aging; homelessness; symptoms; vulnerable populations. $\mathrm{J}$ Gen Intern Med 33(5):635-43 DOI: $10.1007 / \mathrm{s} 11606-017-4229-1$

(c) Society of General Internal Medicine 2017

\section{INTRODUCTION}

Approximately half of the homeless population is aged 50 or older. ${ }^{1}$ Homeless adults in their 50s and 60s have a similar prevalence of geriatric conditions, including functional and cognitive impairment, as adults in their $70 \mathrm{~s}$ and $80 \mathrm{~s}$ in the general population. ${ }^{2,3}$ The majority of homeless adults over 50 have two or more chronic health conditions. ${ }^{4}$ Thus, homeless adults can be considered "older" at age $50 .^{5}$

Symptoms, the self-reported negative perceptions that individuals experience in relation to disease, are prevalent and a common reason for seeking care. ${ }^{6}$ There are four dimensions of symptoms: physical, psychological, social (e.g., loneliness), and existential (those relating to the meaning, purpose, or value of life, e.g., regret and dignity). ${ }^{7}$ The Theory of Symptom Management (TSM) suggests that contextual factors, such as an individual's socioeconomic status, environmental factors, and personal- and health-related factors, affect the experience of symptoms. ${ }^{8,9}$ In the general population, increased age, being a woman, and living in poverty are associated with increased symptom burden. ${ }^{5,10}$

Symptoms have been associated with adverse social and health outcomes including lower quality of life, functional decline, and increased risk of hospitalization or death. ${ }^{11,12,13-}$ 15 The literature on health and homelessness focuses on healthcare utilization and health-related behaviors. There is limited literature on health status focusing on chronic diseases and, more recently, geriatric conditions. ${ }^{2-4}$ Health-related quality of life, to which symptoms are an important contributor, remains understudied. While there are promising advances in treating symptoms in older adults, these have not been 
translated to settings in which people experiencing homelessness receive care. With the aging of the homeless population, there is a heightened need to understand and address symptomatology.

To inform interventions among homeless adults, we describe the prevalence and severity of symptoms in a sample of older adults who currently or recently experienced homelessness. We analyze whether there are associations between sociodemographic characteristics, life conditions, health conditions, health-related behaviors, and other symptom domains, and moderate to severe physical symptoms. Our approach facilitates the identification of modifiable factors for interventions targeted at reducing physical symptom burden. Using cluster analysis, we analyze whether symptom type and severity cluster with one another.

\section{METHODS}

\section{Design Overview}

HOPE HOME (Health Outcomes of People Experiencing Homelessness in Older Middle Age) is a longitudinal study of older homeless adults. We recruited homeless adults aged 50 and older in Oakland, California. ${ }^{2,16-19}$ We interviewed participants every 6 months at a community-based agency serving low-income older adults.

At the 18-month interview, we added an assessment of symptoms. If participants missed the 18-month interview, we administered the symptoms questionnaire at the next interview they attended (Fig. 1). We include participants who completed the symptoms questionnaire in this analysis. We draw data on time-constant characteristics (race, gender) and those in the past (e.g., child abuse) from the baseline interview and timevarying characteristics and symptom assessments from the symptoms interview. The institutional review board of the University of California, San Francisco, approved the study.

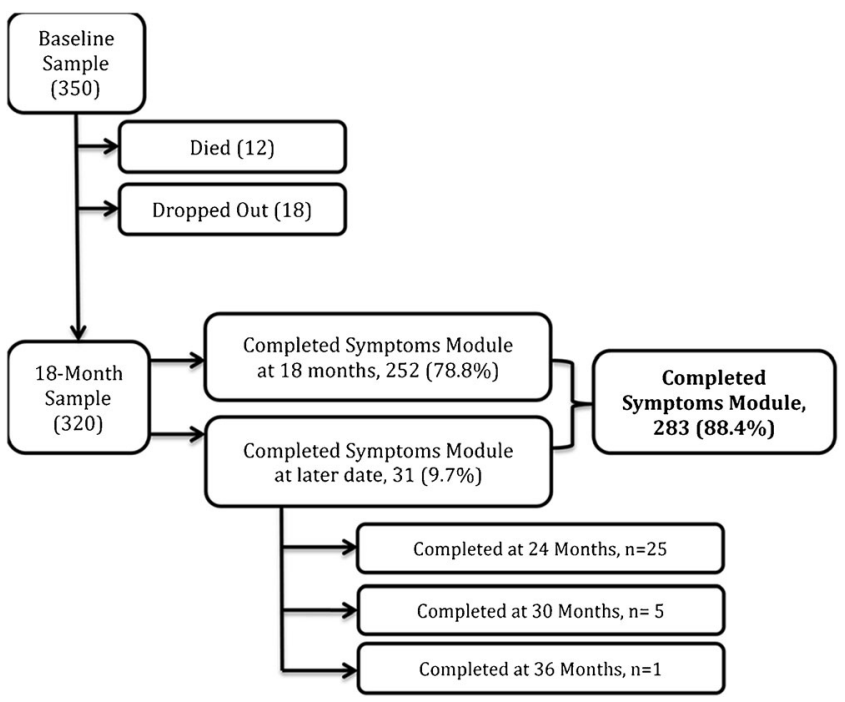

Figure 1 Summary of sample.

\section{Sample}

From July 2013 to June 2014, we recruited 350 homeless adults aged 50 years and older from overnight homeless shelters $(n=5)$, low-cost meal programs $(n=5)$, a recycling center, and places where unsheltered homeless adults stayed. We constructed our sampling frame to approximate the source population and randomly selected potential participants at each recruitment site. ${ }^{19}$ Individuals were eligible to participate in the cohort if, at the first interview, if they were aged 50 or older, English-speaking, and homeless as defined in the federal Homeless Emergency Assistance and Rapid Transition to Housing (HEARTH) Act and able to give informed consent 20,21 .

Trained study staff administered a structured enrollment interview and collected participants' contact information. To ensure follow-up, we asked participants to check in with study staff monthly. If participants missed two or more check-ins, study staff called their contacts and visited places where the participant frequented. We gave participants gift cards to a major retailer: \$25 for the screening and enrollment interview, $\$ 5$ for check-ins, and $\$ 15$ for follow-up interviews.

\section{Primary Dependent Variable: Physical Symptom Burden}

To assess physical symptoms, we administered the validated Patient Health Questionnaire-15 (PHQ-15) at the 18-month interview, which asks about joint pain, fatigue, back pain, sleep trouble, nausea, diarrhea/constipation, shortness of breath, headache, dizziness, stomach pain, palpitations, chest pain, fainting, and sex pain. ${ }^{22}$ We excluded menstrual pain because the sample was over age 50. Participants reported symptoms in the past month as follows: " 0 " (not bothered at all), "1" (bothered a little), or "2" (bothered a lot). We dichotomized symptom burden as $0-9$ (minimal-low) and $\geq 10$ (moderate-high). ${ }^{23}$

\section{Selection of Covariates}

The TSM model asserts that individuals experience symptoms differently based on personal, health-related, and environmental factors. We selected socioeconomic status, environmental factors, social support, health status, prior adverse experiences, health-related behaviors, and the presence of other symptoms as covariates. ${ }^{8}$

\section{Psychological Symptoms}

We examined six psychological symptoms. For depressive symptoms, we considered someone to have symptomatology if they scored $\geq 16$ on the Center for Epidemiologic Studies Depression Scale (CES-D). ${ }^{24,25}$ For post-traumatic stress disorder (PTSD), we considered a score of $\geq 3$ on the Primary Care PTSD (PC-PTSD) four-item screen ${ }^{26,27}$ as indicative of PTSD symptoms. For anxiety, hallucinations, trouble controlling violent behavior, and thoughts of suicide, we used 
individual questions from the Addiction Severity Index $(\mathrm{ASI})^{28}$ as used in the National Survey of Homeless Assistance Providers and Clients (NSHAPC). ${ }^{29}$

Social and Existential Symptoms. Respondents completed the validated Three-Item Loneliness Scale. ${ }^{30}$ Scores of 6-9 indicated loneliness or social symptomatology. ${ }^{31}$ To assess existential symptoms, we measured regret, defined as negative emotions connected to thoughts about how past actions might have achieved better outcomes. ${ }^{32}$ We administered a six-item regret scale. ${ }^{32}$ In the absence of validated cutoff scores for the regret scale, ${ }^{32}$ we used a cutoff of the top quartile of the sample to categorize high regret.

\section{Housing Status}

We assessed housing status at each interview to determine whether participants met HEARTH criteria for homelessness. Participants remained in the study regardless of housing status. We use the term "homeless-experienced," as some participants may have regained housing, but all were homeless when enrolled 18 months earlier. We dichotomized housing status at the symptoms interview as homeless versus housed.

\section{Sociodemographic Data and Recent Life Experiences}

We calculated age at the time of symptoms interview from baseline date of birth. Participants reported demographic characteristics at baseline, including sex, race/ethnicity, and highest level of education, which we dichotomized to less than high school or high school/General Educational Development test equivalency (GED) or higher. We categorized participants who reported "somewhat," "a little," or "not at all" on the question, "How confident are you filling out medical forms by yourself?" as having inadequate health literacy. ${ }^{33}$ Participants reported whether they experienced any episode of physical, verbal, or sexual abuse before age $18 .^{29}$

At the symptoms interview, participants reported any jail or prison time in the prior 6 months. As a measure of social support, we asked participants to report the number of close confidants they had, which we dichotomized to one or more versus none. ${ }^{34}$ Participants reported whether they had experienced any episode of physical, verbal, or sexual abuse in the prior 6 months. ${ }^{29}$

\section{Health-Related Behaviors}

We assessed the following: (1) history of cigarette smoking using questions from the California Tobacco Survey (never, former, or current smoker), ${ }^{35}$ (2) severity of alcohol use using the Alcohol Use Disorders Identification Test (AUDIT; adapted for a 6-month period, score of $\geq 8$ indicated risky or hazardous use of alcohol), ${ }^{36}$ (3) illicit substance use (opioids, methamphetamine, or cocaine) using the World Health Organization Alcohol, Smoking and Substance Involvement Screening Test (ASSIST; 6-month period; score of $\geq 4$ for one or more substances indicated moderate risk substance use). ${ }^{37}$ We assessed cannabis use separately using the same criteria (ASSIST $\geq 4$ ).

\section{Health and Functional Status}

We asked participants whether a healthcare provider had ever told them that they had the following conditions: stroke or transient ischemic attack; coronary artery disease or myocardial infarction; congestive heart failure; chronic obstructive pulmonary disease (COPD), emphysema, chronic bronchitis, or asthma; diabetes; arthritis; cirrhosis or liver disease; kidney disease; cancer; or HIV/AIDS ${ }^{38}$ ( $\geq 2$ indicated multimorbidity).

\section{Healthcare Access}

Participants reported whether they had a regular (nonemergency department) place for care and whether, in the past 6 months, they had needed medical care but were unable to obtain it and/or needed prescriptions but were unable to afford them.

\section{Statistical Analysis}

We described symptom prevalence and participant characteristics using descriptive statistics. Our primary dependent variable is moderate-high physical symptom burden (PHQ-15 score $\geq 10$ ). We assessed bivariate associations between participant characteristics (including psychological, social, and existential symptoms) and moderate-high physical symptoms using Pearson chi-square tests and $t$ tests or the nonparametric Wilcoxon equality of medians test. We selected variables with a statistical significance of $p \geq 0.20$ that we hypothesized may be causally related to physical symptom burden to test in a multivariate logistic model. We reduced the model using $p<0.05$ as the retention criterion.

We used multivariate logistic regression (SAS LOGISTIC procedure) to evaluate the association between selected participant characteristics and moderate-high physical symptom burden. We evaluated potential multicollinearity by comparing the bivariate, starting multivariate, and reduced multivariate model confidence intervals of each independent variable.

Cluster analysis enables us to categorize the experience of symptoms and to investigate the interrelations between environmental factors, as well as psychological, social and existential symptoms, and physical symptom burden. ${ }^{12,39,40}$ We conducted a cluster analysis to classify participants using all four symptom dimensions. Cluster analysis finds existing patterns within data to generate groups by minimizing within-group and maximizing between-group variability. ${ }^{41-45}$ We used the SAS DISTANCE procedure to create a matrix of the multidimensional distance, based on the dichotomous values of each of the 20 physical, psychological, social, and existential symptoms for each participant relative to every other participant. These symptoms included 13 physical symptoms, depression, PTSD, anxiety, hallucinations, violent impulses, loneliness, and 
Table 1 Characteristics of 283 Older Homeless-Experienced Adults in Oakland, CA, and Bivariate Associations with Moderate-High Physical Symptom Burden

\begin{tabular}{|c|c|c|c|c|}
\hline & $\begin{array}{l}\text { Minimal-low } \\
\text { physical symptoms } \\
N=187\end{array}$ & $\begin{array}{l}\text { Moderate-high } \\
\text { physical symptoms } \\
N=96\end{array}$ & $\begin{array}{l}\text { Total } \\
\text { sample } \\
N=\mathbf{2 8 3}\end{array}$ & $P^{*}$ \\
\hline Sociodemographic Information & - & - & - & - \\
\hline Age (years), no. $(\%)$ & _- & _- & _- & 0.42 \\
\hline$<55$ & $39(20.9)$ & $14(14.6)$ & $53(18.7)$ & - \\
\hline $55-59$ & $61(32.6)$ & $33(34.4)$ & $94(33.2)$ & - \\
\hline $60-69$ & $81(43.3)$ & $43(44.8)$ & $124(43.8)$ & - \\
\hline $70+$ & $6(3.2)$ & $6(6.2)$ & $12(4.2)$ & - \\
\hline Female, no. $(\%)$ & $37(19.8)$ & $32(33.3)$ & $69(24.4)$ & 0.01 \\
\hline Race, no. (\%) & - & - & - & 0.24 \\
\hline African-American & $154(82.4)$ & $79(82.3)$ & $233(82.3)$ & - \\
\hline White & $18(9.6)$ & $5(5.2)$ & $23(8.1)$ & - \\
\hline Other & $15(8.0)$ & $12(12.5)$ & $27(9.5)$ & - \\
\hline Less than high school education/General & $41(21.9)$ & $31(32.3)$ & $72(25.4)$ & 0.06 \\
\hline \multicolumn{5}{|l|}{ Education Development (GED), no. (\%) } \\
\hline Inadequate health literacy, no. (\%) & $55(29.4)$ & $46(47.9)$ & $101(35.7)$ & 0.04 \\
\hline Homeless by HEARTH criteria, no. (\%) & $82(43.9)$ & $40(41.7)$ & $122(43.1)$ & 0.73 \\
\hline Jail or prison in last 6 months, no. (\%) & $10(5.3)$ & $7(7.3)$ & $17(6.0)$ & 0.52 \\
\hline Physical, psychological, verbal, or sexual abuse (childhood), no. (\%) & $102(54.5)$ & $63(65.6)$ & $165(58.3)$ & 0.07 \\
\hline Physical, psychological, verbal, or sexual abuse (last 6 months), no. (\%) & $62(33.7)$ & $57(59.4)$ & $119(42.5)$ & $<0.001$ \\
\hline No close confidant & $46(24.7)$ & $22(23.2)$ & $68(24.2)$ & 0.77 \\
\hline Health-related behaviors, no. (\%) & - & - & - & - \\
\hline Past smoker & $32(17.1)$ & $11(11.0)$ & $43(15.2)$ & 0.21 \\
\hline Current smoker & $111(59.4)$ & $67(69.8)$ & $178(62.9)$ & 0.09 \\
\hline Risky to hazardous alcohol use & $11(5.9)$ & $11(11.5)$ & $22(7.8)$ & 0.10 \\
\hline Moderate-risk cannabis use & $61(32.6)$ & $43(44.8)$ & $104(36.7)$ & 0.04 \\
\hline Moderate-risk illicit substance use excluding cannabis & $39(20.9)$ & $27(28.1)$ & $66(23.3)$ & 0.17 \\
\hline Health status, no. $(\%)$ & - & - & - & - \\
\hline Two or more chronic health conditions & $78(41.7)$ & $62(64.6)$ & $140(49.5)$ & $<0.001$ \\
\hline Stroke & $13(7.0)$ & $20(21.1)$ & $33(11.7)$ & 0.001 \\
\hline Congestive heart failure (CHF) & $17(9.1)$ & $9(9.5)$ & $26(9.3)$ & 0.93 \\
\hline Coronary artery disease (CAD)/angina/myocardial infarction (MI) & $15(8.1)$ & $13(13.7)$ & $28(10.0)$ & 0.14 \\
\hline Chronic obstructive pulmonary & $44(23.7)$ & $46(48.4)$ & $90(32.0)$ & $<0.001$ \\
\hline \multicolumn{5}{|l|}{ disease (COPD)/asthma/emphysema/bronchitis } \\
\hline Diabetes & $34(18.3)$ & $17(17.9)$ & $51(18.1)$ & 0.94 \\
\hline Arthritis & $87(46.8)$ & $59(62.1)$ & $146(52.0)$ & 0.02 \\
\hline Cirrhosis/liver disease & $39(21.0)$ & $28(29.5)$ & $67(23.8)$ & 0.11 \\
\hline Kidney disease & $10(5.4)$ & $8(8.4)$ & $18(6.4)$ & 0.32 \\
\hline Cancer & $11(5.9)$ & $5(5.3)$ & $16(5.7)$ & 0.82 \\
\hline HIV/AIDS & $11(6.2)$ & $5(5.6)$ & $16(6.0)$ & 0.84 \\
\hline Healthcare access, no. (\%) & - & - & - & - \\
\hline Have regular healthcare location & $129(70.1)$ & $66(69.5)$ & $195(69.9)$ & 0.91 \\
\hline Unable to obtain needed medical care & $16(8.7)$ & 18 (18.9) & $34(12.2)$ & 0.01 \\
\hline Unable to fill needed prescriptions & $19(10.3)$ & 18 (18.9) & $37(13.2)$ & 0.04 \\
\hline Other symptom dimensions, no. (\%) & - & - & - & - \\
\hline Any psychological symptoms past 6 months & $85(45.5)$ & $78(81.2)$ & $163(57.6)$ & $<0.001$ \\
\hline Moderate to severe depression & $66(35.3)$ & $67(69.8)$ & $133(47.0)$ & $<0.001$ \\
\hline Post-traumatic stress disorder (PTSD) & $24(12.8)$ & $35(36.5)$ & $59(20.8)$ & $<0.001$ \\
\hline Feelings of anxiety & $42.0(22.5)$ & $60.0(62.5)$ & $102(36.0)$ & $<0.001$ \\
\hline Hallucinations & $7(3.8)$ & $22(22.9)$ & $29(10.4)$ & $<0.001$ \\
\hline Violent impulses & $8(4.3)$ & $17(17.7)$ & $25(8.9)$ & $<0.001$ \\
\hline Thoughts of suicide & $2(1.1)$ & $11(11.5)$ & 13 (4.6) & $<0.001$ \\
\hline Loneliness & $57(30.5)$ & $55(57.3)$ & $112(39.6)$ & $<0.001$ \\
\hline Regret & $44(23.5)$ & $31(32.3)$ & $75(26.5)$ & 0.11 \\
\hline
\end{tabular}

*Pearson chi-square analysis and nonparametric equality of medians test

regret. We excluded sexual pain and thoughts of suicide due to low prevalence, which caused clustering of individuals based on the presence of these symptoms alone.

We then used the CLUSTER procedure with Ward's linkage and the TREE procedure to produce a dendrogram representing the structure of the data. Ward's linkage can be sensitive to outliers. ${ }^{45}$ To select an optimal number of clusters, we performed visual analysis of the data and confirmed that we could identify natural groupings by comparing the prevalence of the symptoms in the groupings. We conducted analyses using SAS software, version 9.4 (SAS Institute Inc., Cary, NC).

\section{RESULTS}

\section{Sample Characteristics}

We recruited 350 participants for the baseline sample. ${ }^{19}$ By the 18-month interview, 12 had died and 18 had dropped out. We include the $283(88.4 \%)$ participants who completed the symptoms questionnaire (Fig. 1).

Most individuals in the sample were men and AfricanAmerican, with a median age of 59 years (range 51-82, IQR 55-63). Over half of individuals experienced childhood abuse, and almost half experienced recent abuse. Over a third used 


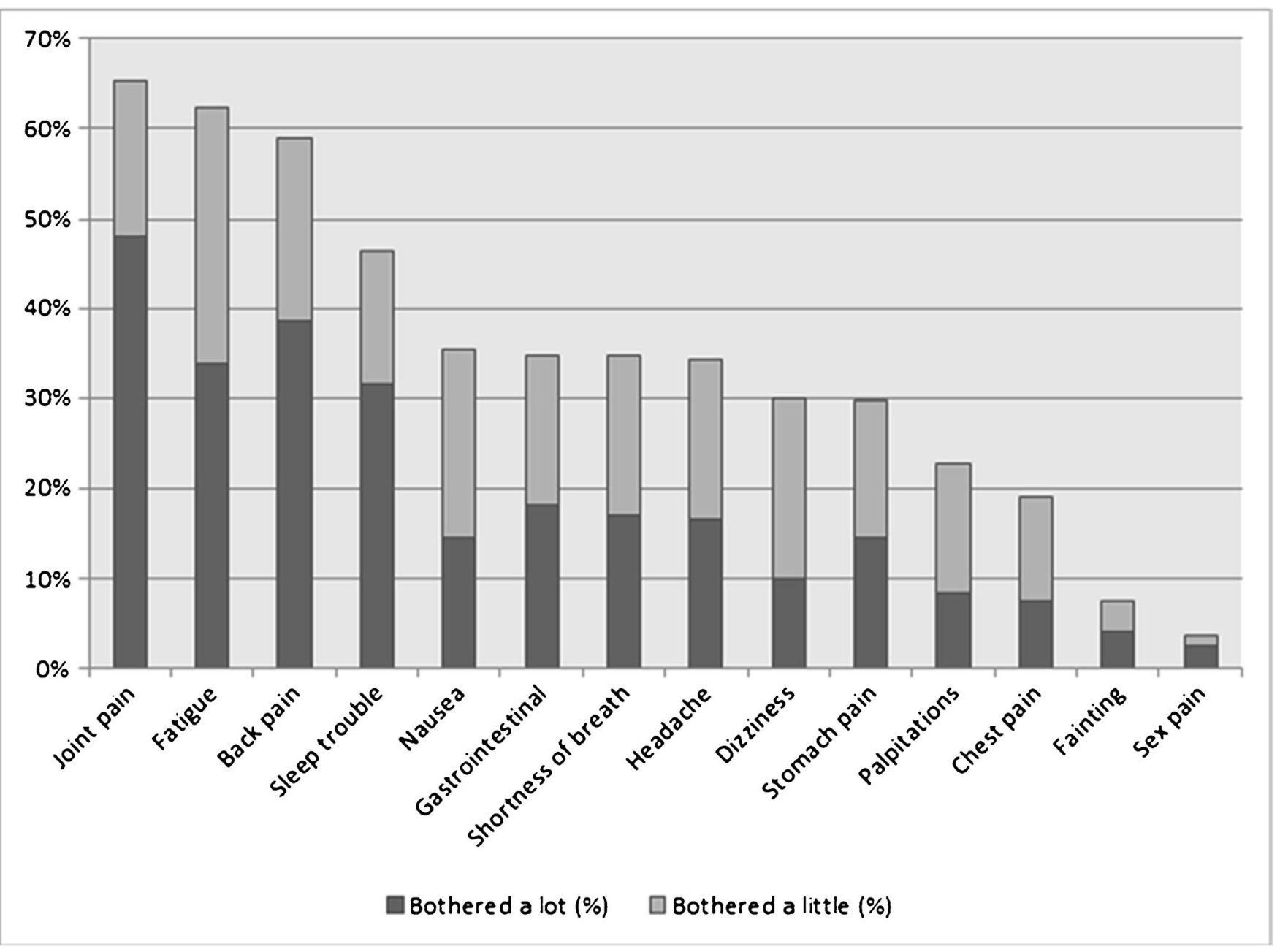

Figure 2 Prevalence and severity of physical symptoms as reported on the Patient Health Questionnaire-15 (PHQ-15) among 283 older homeless-experienced adults in Oakland, CA.

cannabis regularly. Approximately half of the sample suffered from two or more chronic conditions, among which arthritis and pulmonary diseases were most prevalent (Table 1).

\section{Symptom Prevalence}

The median PHQ-15 score was 6.0 (IQR 3.0-11.0), and a third (33.9\%) of the sample had moderate-high physical symptom burden (PHQ-15 score $\geq 10$ ). Joint pain, fatigue, back pain, and sleep problems were the most prevalent and bothersome physical symptoms (Fig. 2). Nearly half of participants reported depressive symptoms; over a third reported anxiety, and a fifth reported PTSD. Over half of the sample had any of the six psychological symptoms we measured. Over a third of participants met loneliness criteria, and over a quarter had regret scores of $\geq 19$ (Table 1).

\section{Factors Associated with Moderate-High Physical Symptom Burden}

In a multivariate analysis, we found that being a woman, experiencing childhood abuse, cannabis use, having two or more chronic conditions, and reporting anxiety, hallucinations, and loneliness were associated with moderate-high physical symptom burden (Table 2). Inadequate health literacy, experiencing abuse in the last 6 months, lacking access to medical care, lacking access to prescriptions, depression, and PTSD were associated with moderate-high symptom burden in bivariate, but not multivariate, analyses. Current housing status (homeless vs. housed) was not associated in bivariate models (Table 1). Our comparison of the bivariate and multivariate models' confidence intervals (CIs) for each independent variable did not indicate multicollinearity.

\section{Cluster Analysis of Physical, Psychological, Social, and Existential Symptoms}

We found four clusters of symptom experience: "minimal symptoms", "moderate symptoms", "high physical, high psychological", and "high physical, low psychological" (Fig. 3). The "minimal symptoms" and "moderate symptoms" clusters differed from one another mainly on physical symptoms, as psychological (means: 1.26 vs. 0.84 , respectively), social ( 0.31 vs. 0.21 ), and existential ( 0.19 vs. 0.22 ) symptoms were similar. The two high physical symptom groups differed on 
Table 2 Factors Associated with Moderate-High Physical Symptoms in Multivariate Regression Model $(N=\mathbf{2 8 3})$

\begin{tabular}{llc}
\hline \hline Characteristics* & $\begin{array}{l}\text { Bivariate, unadjusted } \\
\text { odds ratio } \\
\text { (95\% CI) }\end{array}$ & $\begin{array}{l}\text { Multivariate model, } \\
\text { adjusted odds ratio } \\
\mathbf{( 9 5 \%} \text { CI) }\end{array}$ \\
\hline Female sex & $2.49(1.16-5.37)$ & $2.54(1.28-5.03)$ \\
African-American race & $0.96(0.40-2.34)$ & - \\
Less than high school education/General Education Development (GED) certificate & $1.24(0.59-2.60)$ & - \\
Inadequate health literacy & $1.94(0.95-3.94)$ & - \\
Physical, psychological, verbal, or sexual abuse (childhood) & $2.01(1.02-3.95)$ & $1.88(1.00-3.50)$ \\
Physical, psychological, verbal, or sexual abuse (last 6 months) & $1.43(0.72-2.82)$ & - \\
Risky to hazardous alcohol use & $1.41(0.65-3.07)$ & - \\
Moderate-risk cannabis use & $3.08(1.50-6.30)$ & $2.59(1.38-4.89)$ \\
Moderate-risk illicit substance use (excluding cannabis) & $0.86(0.39-1.88)$ & - \\
Two or more chronic health conditions & $2.86(1.47-5.54)$ & $2.50(1.36-4.58)$ \\
Unable to obtain needed medical care & $2.45(1.19-5.07)$ & - \\
Unable to fill needed prescriptions & $2.04(1.02-4.11)$ & - \\
Moderate to severe depression & $1.57(0.69-3.56)$ & - \\
Post-traumatic stress disorder & $1.33(0.59-3.02)$ & - \\
Feelings of anxiety & $3.29(1.53-7.08)$ & $4.30(2.24-8.26)$ \\
Hallucinations & $2.50(0.80-7.77)$ & $3.77(1.36-10.43)$ \\
Violent impulses & $0.90(0.28-2.91)$ & - \\
Thoughts of suicide & $2.98(0.51-17.5)$ & - \\
Loneliness & $1.67(0.79-3.51)$ & $2.32(1.26-4.28)$ \\
Regret & $0.79(0.24-2.66)$ & - \\
\hline
\end{tabular}

*Variables tested for in the model; italicized variables adjusted for in final model

psychological symptoms but had a similar prevalence of social (means: 0.60 vs. 0.65 , respectively) and existential ( 0.33 vs. 0.37 ) symptoms. All clusters demonstrated predominance of joint pain, back pain, fatigue, and sleep trouble.

\section{DISCUSSION}

In a cohort study of older homeless-experienced adults, we found a high prevalence of symptomatology across multiple domains. We found that symptom domains clustered together: those with higher physical symptomatology had a high prevalence of other symptom domains. The factors associated with physical symptoms were similar to those in the general population (being a woman, having experienced childhood abuse, psychological symptoms [anxiety], and chronic medical conditions), and others that are less well described (loneliness, high-risk cannabis use, and hallucinations). ${ }^{46-49}$.

The four most prevalent physical symptoms are similar to those found in other populations studied: those related to pain and fatigue. ${ }^{5,50}$ We hypothesized that environmental factors may contribute to these experiences: homeless adults live in challenging environments where they have little privacy, are exposed to weather, noise, and safety risks, and lack appropriate bedding. These conditions interfere with sleep and can increase pain and fatigue; homeless individuals are twice as likely to report sleeping less than $4 \mathrm{~h}$ a night as those in the general population. ${ }^{51}$ However, we did not find an independent association between current homelessness (vs. having regained housing) and high physical symptomatology, suggesting that environmental factors alone do not explain these findings. Rather, the high prevalence of symptoms is likely due to more complex contextual factors, including comorbid medical and psychological conditions.

The association between physical symptoms and anxiety mirrors that in the general population. There is an increasing recognition of the role of anxiety in the causal pathway for both pain and poor sleep quality. ${ }^{52-54}$ Somatization is an established cause of physical symptoms secondary to mental illness, particularly anxiety. ${ }^{55}$ Anxiety may present with physical symptoms such as palpitations, ${ }^{56}$ but the experience may be bidirectional. Higher physical illness burden correlates with higher anxiety symptomatology due to health anxiety and stress related to illness. ${ }^{57}$ In our analysis of symptom clusters, we did not find any groups with a high prevalence of psychological symptoms that did not also have a high prevalence of physical symptoms. Clinicians attempting to address physical symptoms in older homeless-experienced adults should assess for, and treat, anxiety. Our finding that hallucinations are independently associated with physical symptoms warrants further research. Hallucinations may serve as a marker for increased severity of mental health problems or for other conditions.

We found a prevalence of loneliness higher than the estimated prevalence among older adults in the general population. ${ }^{58}$ Loneliness is a predictor of mortality and functional decline in older adults. ${ }^{11}$ Our sample shared many known risk factors for loneliness including older age, low income, social isolation, and poorer physical and mental health. ${ }^{59}$ Clinicians and policymakers concerned with improving outcomes in older adults with experiences of homelessness should address loneliness, because it is a source of distress and may increase the experience of other forms of symptomatology. Shelter and housing interventions could address loneliness by encouraging meaningful interactions that build a sense of community through specifically targeted group activities. ${ }^{60}$ 


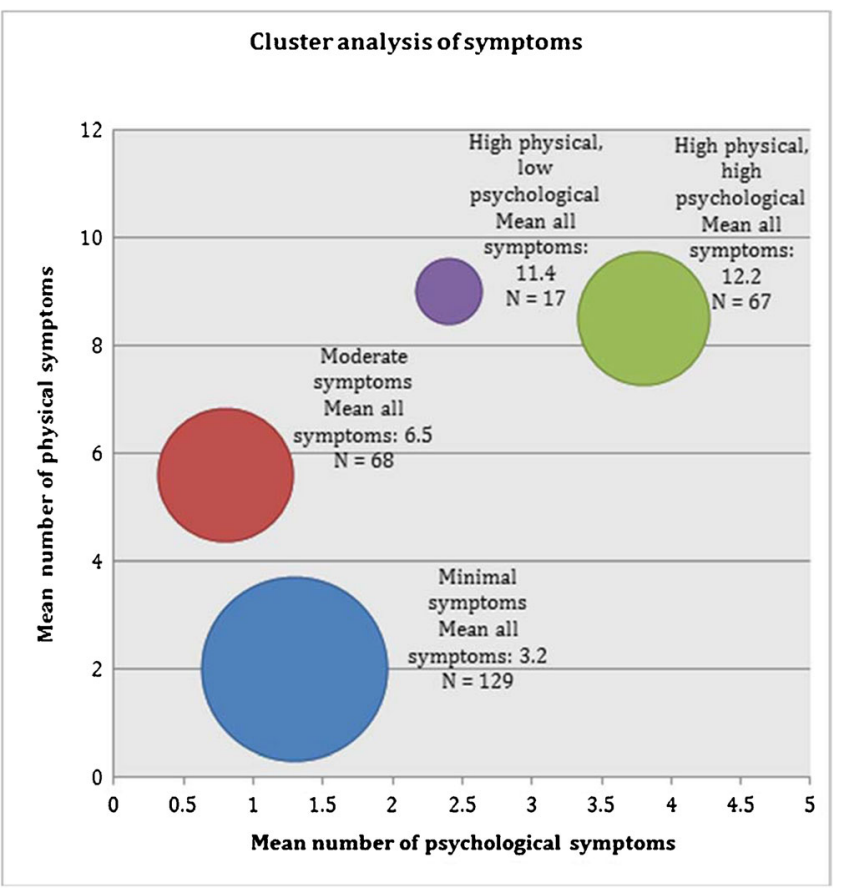

Figure 3 Cluster analysis of physical, psychological, social, and existential symptoms showing size of cluster and mean number of symptoms.

While we found a bivariate association between unmet need for healthcare/prescriptions and higher physical symptom burden, the association did not persist in multivariate analysis. Symptoms may be less reflective of poor access to medical care and more reflective of the other contextual factors. For example, the association of physical symptoms with childhood abuse, even in a population with a high prevalence of these experiences, suggests the enduring effects of childhood abuse on overall well-being.

There are a number of promising interventions in the general population focused on symptom control which should be modified for use in this population. Among urban homebound chronically ill patients, a home-based primary and palliative care (HBPC) program led to significant symptom reduction. ${ }^{61}$ The HBPC program included a multidisciplinary team of healthcare and community-based social service providers. This model can be adapted to existing healthcare delivery programs that provide medical services in places where currently and formerly homeless people live. Clinics that focus on homeless populations can adapt best practices from palliative care to provide clinic-based symptom management. These include integrated models of care which provide avenues for behavioral health integration and the use of adjuvant services (i.e., exercise and wellness classes, complementary treatments, and group activities), which could be adjusted to address the severe burden of symptomatology.

Our study has several limitations. As there is no goldstandard estimate of the number of people experiencing homelessness, it is not possible to recruit a representative sample. Instead, we used best practices to build a cohort that approximates the true population. ${ }^{16-18}$ While all study participants were homeless at study entry, over half had exited homelessness at the time of their symptoms interview. As homelessness is a state characterized by frequent entrances and exits, our study provides a realistic description of the experience of homelessness. There was likely non-random loss to follow-up. The most ill participants may have died prior to the symptom survey, leading us to underestimate symptom burden. Those who dropped out or were lost to follow-up may have been more or less symptomatic. We cannot interpret causality. Finally, the regret scale did not have population norms; as we used the top quartile of responses to signify high regret, we cannot make statements about the relative prevalence.

Clinicians working with older homeless adults should screen for and address symptomatology, including physical, psychological, social, and existential symptoms, drawing lessons from those learned by palliative care clinicians. Existing models could be adapted for use in clinical settings of care for homeless-experienced populations. The high degree of distressing symptoms experienced by this population calls for patient-centered interventions that reduce suffering.

Corresponding Author: Margot Kushel, MD; UCSF Division of General Internal Medicine at Zuckerberg San Francisco General Hospital, San Francisco, CA, USA (e-mail: margot.kushel@ucsf.edu).

Contributors We gratefully acknowledge our colleagues Pamela Olsen, Nina Fiellin, Tauni Marin, and Kenneth Perez for their invaluable contributions to the HOPE HOME study. We would like to acknowledge our colleague Angela Allen, who passed away in May of 2015, for her incredible contributions to the study. The authors also thank the staff at St. Mary's Center and the HOPE HOME Community Advisory Board for their guidance and partnership. We acknowledge Lauren M. Kaplan, PhD, for her contributions to the revisions of this manuscript.

Funders This study was funded by grants from the National Institute on Aging at the National Institutes of Health [K24AG046372, R01AG041860, and P3OAG044281] and by the National Institute on Minority Health and Health Disparities [R25MD006832]. These funding sources had no role in the preparation, review, or approval of the manuscript.

\section{Compliance with Ethical Standards:}

Conflict of Interest: All authors declare that they have no conflict of interest.

Prior Presentations: American Public Health Association meeting, October 2016.

\section{REFERENCES}

1. Culhane DP, Metraux S, Byrne T, et al. The age structure of contemporary homelessness: evidence and implications for public policy. Analyses Soc Issues Public Policy 2013;13(1):228-244.

2. Brown RT, Hemati $\mathbf{K}$, Riley ED, et al. Geriatric conditions in a population-based sample of older homeless adults. Gerontologist 2017:57(4):757-766 
3. Brown RT, Kiely DK, Bharel M, et al. Geriatric syndromes in older homeless adults. J Gen Intern Med 2012;27(1):16-22.

4. Garibaldi B, Conde-Martel A, O'Toole TP. Self-reported comorbidities, perceived needs, and sources for usual care for older and younger homeless adults. J Gen Intern Med 2005;20(8):726-730.

5. Eckerblad J, Theander $\mathbf{K}$, Ekdahl A, et al. Symptom burden in community-dwelling older people with multimorbidity: a cross-sectional study. BMC Geriatr 2015;15: 1.

6. Rosendal M, Carlsen AH, Rask MT, et al. Symptoms as the main problem in primary care: A cross-sectional study of frequency and characteristics. Scand J Prim Health Care 2015;33(2):91-99.

7. Bolano $\mathbf{M}$, Ahalt $\mathbf{C}$, Ritchie C, et al. Detained and distressed: persistent distressing symptoms in a population of older jail inmates. J Am Geriatr Soc 2016;64(11):2349-2355.

8. Brant JM, Beck S, Miaskowski C. Building dynamic models and theories to advance the science of symptom management research. J Adv Nurs 2010;66(1):228-240.

9. Dodd M, Janson S, Facione N, et al. Advancing the science of symptom management. J Adv Nurs 2001;33(5):668-676.

10. Silveira MJ, Kabeto MU, Langa KM. Net worth predicts symptom burden at the end of life. J Palliat Med 2005;8(4):827-837.

11. Perissinotto CM, Stijacic Cenzer I, Covinsky KE. Loneliness in older persons: a predictor of functional decline and death. Arch Intern Med 2012;172(14):1078-1083.

12. Walke LM, Byers AL, Gallo WT, et al. The association of symptoms with health outcomes in chronically ill adults. J Pain Symptom Manag 2007;33(1):58-66.

13. Wrosch C, Bauer I, Miller GE, et al. Regret intensity, diurnal cortisol secretion, and physical health in older individuals: evidence for directional effects and protective factors. Psychol Aging 2007;22(2):319-330.

14. Sha MC, Callahan CM, Counsell SR, et al. Physical symptoms as a predictor of health care use and mortality among older adults. Am J Med 2005; 118(3):301-306.

15. Eckerblad J, Theander K, Ekdahl A, et al. To adjust and endure: a qualitative study of symptom burden in older people with multimorbidity. Appl Nurs Res 2015;28(4):322-327.

16. Burnam MA, Koegel P. Methodology for obtaining a representative sample of homeless persons - The Los Angeles Skid Row Study. Eval Rev 1988;12(2):117-152.

17. Moss AR, Hahn JA, Perry S, et al. Adherence to highly active antiretroviral therapy in the homeless population in San Francisco: a prospective study. Clin Infect Dis. 2004;39(8):1190-1198.

18. US Census Bureau. National Survey of Homeless Assistance Providers and Clients (NSHAPC): Public Use Data Files Clients. 1999; Available at: http://www.census.gov/prod/www/nshapc/NSHAPC4.html. Accessed 25 Oct 2017.

19. Lee CT, Guzman D, Ponath C, Tieu L, Riley E, Kushel M. Residential patterns in older homeless adults: results of a cluster analysis. Soc Sci Med 2016;153:131-140.

20. Homeless Emergency Assistance and Rapid Transition to Housing Act of 2009. Definition of homelessness., P.L. 111-22, Sec. 1003. 111th Congress ed; U.S. Congress. 2009. 35. Al-Delaimy WK, Edland S, Pierce JP, et al. California Tobacco Survey (CTS): 2008. (Version 1). Available at: http://hdl.handle.net/ UCSD/10026 California Department of Health Services. 2011. Accessed 22 Nov 2017.

21. Dunn LB, Jeste DV. Enhancing informed consent for research and treatment. Neuropsychopharmacology. 2001;24(6):595-607.

22. Kroenke K, Spitzer RL, Williams JB. The PHQ-15: validity of a new measure for evaluating the severity of somatic symptoms. Psychosom Med 2002;64(2):258-266.

23. Lee S, Creed FH, Ma YL, Leung CM. Somatic symptom burden and health anxiety in the population and their correlates. J Psychosom Res 2015;78(1):71-76.

24. Wong Y-LI. Measurement properties of the Center for Epidemiologic studies-Depression Scale in a homeless population. Psychol Assess 2000;12(1):69-76.

25. Haringsma R, Engels GI, Beekman AT, Spinhoven P. The criterion validity of the Center for Epidemiological Studies Depression Scale (CESD) in a sample of self-referred elders with depressive symptomatology. Int J Geriatr Psychiatry 2004;19(6):558-563.

26. Ouimette P, Wade M, Prins A, Schohn M. Identifying PTSD in primary care: comparison of the Primary Care-PTSD screen (PCPTSD) and the General Health Questionnaire-12 (GHQ). J Anxiety Disord 2008;22(2):337-343.

27. van Dam D, Ehring T, Vedel E, Emmelkamp PM. Validation of the Primary Care Posttraumatic Stress Disorder screening questionnaire (PC-
PTSD) in civilian substance use disorder patients. J Subst Abus Treat 2010;39(2): 105-113

28. Cacciola JS, Pecoraro A, Alterman AI. Development of ASI psychiatric severity cut-off scores to identify co-occurring psychiatric disorders. Int $\mathrm{J}$ Ment Heal Addict. 2008;6(1):77-92.

29. Burt MR, et al. United States. Interagency Council on the Homeless., \& Urban Institute. Homelessness: programs and the people they serve: findings of the National Survey of Homeless Assistance Providers and Clients: summary report. Washington, DC: U.S. Dept. of Housing and Urban Development. 1999.

30. Hughes ME, Waite LJ, Hawkley LC, Cacioppo JT. A short scale for measuring loneliness in large surveys: results from two population-based studies. Res Aging 2004;26(6):655-672.

31. Herrera-Badilla A, Navarrete-Reyes AP, Amieva H, Avila-Funes JA. Loneliness is associated with frailty in community-dwelling elderly adults. J Am Geriatr Soc 2015;63(3):607-609.

32. Roese NJ, Epstude KAI, Fessel F, et al. Repetitive regret, depression, and anxiety: findings from a nationally representative survey. J Soc Clin Psychol 2009;28(6):671-688.

33. Chew LD, Griffin JM, Partin MR, et al. Validation of screening questions for limited health literacy in a large VA outpatient population. J Gen Intern Med 2008;23(5):561-566.

34. Gielen AC, McDonnell KA, Wu AW, O'Campo P, Faden R. Quality of life among women living with HIV: the importance violence, social support, and self care behaviors. Soc Sci Med 2001;52(2):315-322.

35. Al-Delaimy WK, Edland S, Pierce JP, Mills AL, White MM. California Tobacco Survey (CTS): 2008. California Department of Health Services. 2011.

36. Babor TF, Higgins-Biddle JC, Saunders JB, et al. The alcohol use disorders identification test: guidelines for use in primary care. Geneva: World Health Organization; 2001. Available at: http://apps.who.int/iris/ handle/10665/67205. Accessed 25 Oct 2017.

37. Humeniuk R, Henry-Edwards S, Ali R, Poznyak V, Monteiro M. The Alcohol, Smoking and Substance Involvement Screening Test (ASSIST): Manual for use in primary care. Geneva: World Health Organization;2010.

38. Centers for Disease Control and Prevention (CDC). National Center for Health Statistics (NCHS). National Health and Nutrition Examination Survey Questionnaire (NHANES). Hyattsville, MD: U.S. Department of Health and Human Services, Centers for Disease Control and Prevention; 2009. Available at: https://wwwn.cdc.gov/nchs/nhanes/ContinuousNhanes/Default.aspx?BeginYear=2009. Accessed 25 Oct 2017.

39. Yates P, Miaskowski C, Cataldo JK, et al. Differences in composition of symptom clusters between older and younger oncology patients. J Pain Symptom Manag 2015;49(6):1025-1034.

40. Fishbain D, Gao JR, Lewis J, Bruns D, Meyer LJ, Disorbio JM. Examination of symptom clusters in acute and chronic pain patients. Pain Physician 2014;17(3):E349-357.

41. Huntington N, Buckner JC, Bassuk EL. Adaptation in homeless children: an empirical examination using cluster analysis. Am Behav Sci. 2008;51(6):737-755.

42. Kuhn R, Culhane DP. Applying cluster analysis to test a typology of homelessness by pattern of shelter utilization: results from the analysis of administrative data. Am J Community Psychol 1998;26(2):207-232.

43. Danseco ER, Holden EW. Are there different types of homeless families? a typology of homeless families based on cluster analysis. Fam Relat 1998;47(2): 159-165.

44. Kaufman L, Rousseeuw PJ. Finding Groups in Data: An Introduction to Cluster Analysis. New York: Wiley-Interscience; 1990.

45. Everitt BS, Landau S, Leese M, Stahl D. Cluster Analysis. Chichester: Wiley; 2011.

46. Hinz A, Ernst J, Glaesmer H, et al. Frequency of somatic symptoms in the general population: normative values for the Patient Health Questionnaire-15 (PHQ-15). J Psychosom Res 2017;96:27-31.

47. McCauley J, Kern DE, Kolodner K, et al. Clinical characteristics of women with a history of childhood abuse: unhealed wounds. JAMA 1997;277(17):1362-1368.

48. Katon W, Lin EHB, Kroenke $\mathbf{K}$. The association of depression and anxiety with medical symptom burden in patients with chronic medical illness. Gen Hosp Psychiatry 2007;29(2):147-155.

49. Kempen GI, Ormel J, Brilman EI, Relyveld J. Adaptive responses among Dutch elderly: the impact of eight chronic medical conditions on health-related quality of life. Am J Public Health 1997;87(1):38-44.

50. Reilly CM, Bruner DW, Mitchell SA, et al. A literature synthesis of symptom prevalence and severity in persons receiving active cancer treatment. Support Care Cancer. 2013;21(6):1525-1550. 
51. Léger D, Beck F, Richard J. Sleep loss in the homeless-an additional factor of precariousness: Survey in a group of homeless people. JAMA Intern Med. 2017;177(2)278-279.

52. Ramsawh HJ, Stein MB, Belik S-L, Jacobi F, Sareen J. Relationship of anxiety disorders, sleep quality, and functional impairment in a commu nity sample. J Psychiatr Res 2009;43(10):926-933.

53. Magee JC, Carmin CN. The relationship between sleep and anxiety in older adults. Curr Psychiatry Rep 2010;12(1):13-19.

54. Woo AKM. Depression and anxiety in pain. Rev Pain 2010;4(1):8-12.

55. Ladwig K-H, Marten-Mittag B, Erazo N, Gündel H. Identifying somatization disorder in a population-based health examination survey: psychosocial burden and gender differences. Psychosomatics 2001;42(6):511-518.

56. Gelenberg AJ. Psychiatric and somatic markers of anxiety: identification and pharmacologic treatment. Prim Care Companion J Clin Psychiatr. 2000;2(2):49-54.
57. Hirsch JK, Walker KL, Chang EC, Lyness JM. Illness burden and symptoms of anxiety in older adults: optimism and pessimism as moderators. Int Psychogeriatr 2012;24(10):1614-1621.

58. Ong AD, Uchino BN, Wethington E. Loneliness and health in older adults: a mini-review and synthesis. Gerontology 2016;62(4):443-449.

59. Cohen-Mansfield J, Hazan H, Lerman Y, Shalom V. Correlates and predictors of loneliness in older-adults: a review of quantitative results informed by qualitative insights. Int Psychogeriatr 2016;28(4):557-576.

60. Cohen-Mansfield J, Perach R. Interventions for alleviating loneliness among older persons: a critical review. Am J Health Promot. 2015;29(3):e109-125.

61. Ornstein $\mathbf{K}$, Wajnberg A, Kaye-Kauderer $\mathbf{H}$, et al. Reduction in symptoms for homebound patients receiving home-based primary and palliative care. J Palliat Med 2013;16(9):1048-1054. 